\title{
Systemic lupus erythematosus patient guide: influence on knowledge of the disease
}

Yriö T Konttinen, Nina Santavirta, Visa Honkanen, Singa Sandelin, Leonora Schauman, Mats Grönblad

\begin{abstract}
The knowledge of patients with systemic lupus erythematosus about their disease before and after reading a patient guide was tested. The scores for incorrect answers decreased from 28 to $24 \%$ after reading the guide, showing that it increased the patients' knowledge of the disease. The patients with an academic background had the best scores before reading the guide, but they did not improve their scores as much as patients with lower educational qualifications. The differences between the groups studied were not significant in a one way analysis of variance. Forty seven questions about the psychology and coping mechanisms of the patients were factorised. These factors, together with data on the duration and severity of SLE and the age of the patient, were used in multiple linear regression analysis, but had no significant predictive value for an improvement in knowledge. The scores in psychological tests were the same before and after reading the guide. It is concluded that the patient guide for SLE increases knowledge of the disease, but does not affect the psychological response of the patient. The improvement in knowledge cannot be predicted on the basis of various psychological and clinical factors or the social background of the patient.
\end{abstract}

Systemic lupus erythematosus is a chronic multisymptomatic disease ${ }^{1}$ and, as a result of its variability and unpredictable course, can cause considerable psychological stress to patients. Psychiatric consultations are needed considerably more often than for patients with, for example, rheumatoid arthritis. The most common mental disorders in SLE are depression and adjustment disorders. ${ }^{2}$

It is generally considered that in this kind of chronic disease it is beneficial for a patient to obtain as much scientifically valid and comprehensive information of the disease as possible. There is some theoretical basis for this: it has been shown that the inhibition of feelings of disappointment and disclosing of traumas results in an increase of autonomic nervous activity and changes in the immune system. ${ }^{34}$ In chronic illnesses the complete disclosure of the traumatic factor (the disease) is impossible. In these situations the subject uses several coping mechanisms to maintain psychophysical integrity; the more successful the coping is, the less often the patient has psychiatric disorders. The main coping strategies are information seeking, direct action, inhibition, the intrapsychic process, and seeking social support (Lazarus $\mathbf{R}$, Conference on the critical evaluation of behavioural paradigms for psychiatric science; 1978 Nov 3-6).

We edited and published a guidebook for patients with SLE. In addition to advice on general problems and social insurance, it included comprehensive clinical information on the disease. It can be speculated that the patients with well developed coping strategies for seeking information would benefit most from the guidebook. It is also logical to expect that obtaining information decreases the need for the other coping mechanisms and decreases psychological distress. However, studies of the effect of this kind of guidebook have not yet been published. Therefore, we evaluated the patients' knowledge of their disease before and after they had read the guide. We compared the changes in knowledge with coping mechanisms, psychological features, and social background and tried to find answers to three questions: $(a)$ does reading the guide improve the patient's knowledge of her/his disease; (b) does this improvement in knowledge correlate with psychological parameters and lead to any changes in these parameters; and $(c)$ are the social and clinical anamnestic factors significant in this context.

\section{Patients and methods}

PATIENTS

The prevalence of SLE in Finland ${ }^{5}$ was 28 per 100000 in December 1978, when the population of Finland was 4758008 . This means that there is a total of $1300-1400$ patients with SLE in Finland. No guides for patients with SLE were available in Finnish until 1988, when we edited and wrote a comprehensive guidebook for SLE of 45 pages. It was distributed at random to 90 patient members of the Finnish Lupus Society.

Sixty six patients (five men, 61 women) with classical SLE participated in this study. ${ }^{6}$ The mean (SD) age was 37 (10) years and the duration of the disease $9(7 \cdot 5)$ years. The severity of the disease was assessed as mild or severe according to the symptoms. In this study SLE was regarded as severe if the patient had had kidney involvement, epileptic seizures, or severe necrotising vasculitis. Table 1 shows the social background of the patients. The patients' knowledge of SLE was tested before and eight to 10 weeks after reading the guide (table 2). The patients were told not to look up the correct answers in the guidebook. The general activity of the patient in information seeking was evalu- 
Table 1 Social background of the patients

\begin{tabular}{ll}
\hline & $\begin{array}{l}\text { Number of } \\
\text { patients }\end{array}$ \\
\hline Education & \\
Basic school & 28 \\
Trade school & 13 \\
Academic & 25 \\
Marital status & \\
$\quad$ Married & \\
Unmarried, but living with partner & 24 \\
Single & 20 \\
Living area & \\
$\quad$ City & 35 \\
Town or village & 21 \\
Countryside & 10 \\
\hline
\end{tabular}

Table 2 Questions used in testing the knowledge of the patients before and after reading the guide. The patient can give one of five alternative answers to each question, from 'absolutely true' to 'absolutely false'

1 Systemic lupus erythematosus is a versatile disease and can be different in each patient

2 SLE can cause severe pain in the joints, but the disease seldom leads to permanent damage of joint cartilage and bone

3 Pregnancy is nearly always problematic in SLE

4 SLE is as common in men as in women

5 Oestrogen containing birth control pills are harmless for most patients with SLE

The ideal diastolic blood pressure for the patient with SLE is less than 90 (anyway less than 100)

7 In the treatment of SLE, glucocorticoids (cortisone) can be used for long periods without any major side effects

8 The patient with SLE can obtain financial support for dentistry only for an inflammatory condition or tooth extraction

ated with seven questions concerning the use of different information sources.

\section{METHODS}

In the psychological testing we used a pretested instrument to assess various psychological aspects and coping strategies. ${ }^{7}$ The instrument was chosen on the basis of previous research on the psychological aspects and coping mechanisms of patients with painful chronic diseases. ${ }^{89}$ Before the final version of the total instrument was used a pilot study was carried out. Ten patients with SLE answered the questionnaire, including the items concerning knowledge of SLE. After evaluating the pilot study minor modifications were made to the questionnaire.

\section{STATISTICAL ANALYSIS}

The BMDP statistical software package was used in the analyses. The original 47 questions on the psychology and coping mechanisms of the patients were factorised. ${ }^{10} \mathrm{We}$ applied the maximum likelihood method with an eigen value limit greater than two when extracting the factors. In this way the questions were clustered in seven factors. After direct quartimin rotation we selected three questions with largest loading from each factor (table 3). These three questions then represented the factor in later analyses.

The differences in knowledge and in factors before and after reading the guidebook were compared using a paired $t$ test and the Wilcoxon signed rank test. The possible effect of the category variables on the changes in knowledge were evaluated using a one way analysis of
Table 3 Factors considered in analysis of statistical significance

\begin{tabular}{|c|c|}
\hline $\begin{array}{l}\text { Factor 1: Self care } \\
\text { Questions (loadings) }\end{array}$ & $\begin{array}{l}1 \text { In my opinion I take good care of my } \\
\text { health (0.638) } \\
2 \text { I try to live and act as I think and feel } \\
(0 \cdot 609) \\
3 \text { I know what I want from life }(0.546)\end{array}$ \\
\hline $\begin{array}{l}\text { Factor 2: General family } \\
\text { Questions (loadings) }\end{array}$ & $\begin{array}{l}\text { relationships } \\
1 \text { How does your family respond to the } \\
\text { problems caused by your illness? } \\
(0 \cdot 709) \\
2 \text { How have you generally coped with } \\
\text { your family recently? ( } 0.648) \\
3 \text { How would you describe your } \\
\text { relationship to other persons who } \\
\text { are close to you? (0.541) }\end{array}$ \\
\hline $\begin{array}{l}\text { Factor 3: Self confidence } \\
\text { Questions (loadings) }\end{array}$ & $\begin{array}{l}1 \text { I prefer to communicate with people } \\
\text { with the same background as myself } \\
\text { (0.815) } \\
2 \text { Humans can influence their own } \\
\text { health }(0.534) \\
3 \text { I stick to my opinion if I think I am } \\
\text { right }(0.435)\end{array}$ \\
\hline $\begin{array}{l}\text { Factor 4: Self reflection } \\
\text { Questions (loadings) }\end{array}$ & $\begin{array}{l}1 \text { My disease has made me thoroughly } \\
\text { reconsider my situation }(0.794) \\
2 \text { It felt very distressing to fall ill } \\
\text { (0.623) } \\
3 \text { It feels important to evaluate one's } \\
\text { life }(0.526)\end{array}$ \\
\hline $\begin{array}{l}\text { Factor 5: Flexibility } \\
\text { Questions (loadings) }\end{array}$ & $\begin{array}{l}1 \text { I feel that I really enjoy my life } \\
(0.623) \\
2 \text { I prefer my friends to share my } \\
\text { opinions }(0.597) \\
3 \text { I am attracted by individual charac- } \\
\text { teristics in persons I get acquainted } \\
\text { with }(0.579)\end{array}$ \\
\hline $\begin{array}{l}\text { Factor 6: Partner relation } \\
\text { Questions (loadings) }\end{array}$ & $\begin{array}{l}\text { aships } \\
1 \text { How would you describe your } \\
\text { relationship to you wife/husband/ } \\
\text { partner before falling ill? (0.976) } \\
2 \text { Has your disease condition changed } \\
\text { your relationship to your wife/ } \\
\text { husband/partner? (0.758) } \\
3 \text { Is your sexual interest reduced owing } \\
\text { to the disease? }(0 \cdot 357)\end{array}$ \\
\hline $\begin{array}{l}\text { Factor 7: Anxiety } \\
\text { Questions (loadings) }\end{array}$ & $\begin{array}{l}1 \text { It is not necessary to express every- } \\
\text { thing with words-people should } \\
\text { also be able to read between the lines } \\
\text { (0.673) } \\
2 \text { One should try to avoid insulting } \\
\text { other persons (0.409) } \\
3 \text { People who do not share my taste do } \\
\text { not attract me }(0.423)\end{array}$ \\
\hline
\end{tabular}

variance. ${ }^{11}$ We finally conducted a stepwise multiple linear regression analysis to find out the psychological factors which might explain the differences in the improvement of knowledge of the disease. ${ }^{12}$

\section{Results}

The patients' knowledge of SLE significantly improved after reading the guide $(p<0.001)$. The patients with an academic educational background had the best score before reading the guide, but they did not improve as much as the patients with lower educational qualifications. Table 4 shows that the differences between the groups did not reach statistical significance. In the stepwise multiple regression analysis we studied the possible explanations for the improvement of knowledge, including sex, age, the duration and severity of the disease, and various psychological factors (self care, general family relationships, self confidence, self reflection, flexibility, relationships with partners, anxiety; table 3). None of these factors 
Table 4 Knowledge score before and after reading the guide for patients with different educational backgrounds. The $p$ value for the overall difference between groups was 0.2922 . The score is for incorrect answers

\begin{tabular}{llll}
\hline & $\begin{array}{l}\text { Basic school } \\
(n=28)\end{array}$ & $\begin{array}{l}\text { Trade school } \\
(n=13)\end{array}$ & $\begin{array}{l}\text { Academic } \\
(n=25)\end{array}$ \\
\hline $\begin{array}{l}\text { Before } \\
\text { After }\end{array}$ & 28 & 29 & 26 \\
\hline
\end{tabular}

Table 5 Scores (mean (SD)) for psychological factors before and after reading the guide

\begin{tabular}{lcr}
\hline Factor & Before & \multicolumn{1}{l}{ After } \\
\hline Self care & $6 \cdot 8(1 \cdot 8)$ & $.6 \cdot 6(1 \cdot 7)$ \\
General family relationships & $6 \cdot 6(2 \cdot 3)$ & $6 \cdot 6(2 \cdot 3)$ \\
Self confidence & $5 \cdot 7(1 \cdot 5)$ & $5 \cdot 8(1 \cdot 3)$ \\
Self reflection & $5 \cdot 8(1 \cdot 9)$ & $6 \cdot 0(1 \cdot 9)$ \\
Flexibility & $7 \cdot 8(1 \cdot 9)$ & $7 \cdot 5(1 \cdot 6)$ \\
Partner relationships & $10 \cdot 7(3 \cdot 9)$ & $11 \cdot 0(4 \cdot 3)$ \\
Anxiety & $10 \cdot 6(1 \cdot 8)$ & $10 \cdot 4(1 \cdot 7)$ \\
\hline
\end{tabular}

had a significant predictive value for the improvement. Table 5 shows that the scores in the psychological tests were almost the same before and after reading the guide.

\section{Discussion}

It is widely accepted that verbal, personal information is better received than written information. Owing to the practical difficulties in conducting a population based study, we studied members of The Finnish Lupus Society. There are 500 members in the society; 1200 patients in Finland have a verified diagnosis of SLE. The patients were chosen at random and thus represented the average SLE patient population. Information booklets are not available in Finnish, but some of the more educated members of the society might have absorbed information from international publications. The lack of relevant information on SLE in Finnish has been acknowledged by the members of the society and they were highly motivated to participate in this investigation. When the learning processes in patients with SLE is analysed a confounding factor is the possible memory impairment in patients with central nervous system disease or in those receiving corticosteroids. Our study showed that knowledge of SLE can be significantly improved with a comprehensive guidebook. These results can be extrapolated into real life, in which the patients obtain a guidebook during a routine consultation.

There was no statistically significant association between educational background and the improvement in knowledge after reading the guidebook. However, patients educated at technical college showed the largest improvement in knowledge. It is possible that patients with an academic background are more experienced in using fragmented sources of informa- tion, so the guidebook does not offer them much further help.

In addition to social background, variables related to psychological factors and coping mechanisms were assessed. These variables were self care, general family relationship, self confidence, self reflection, flexibility, relations with partners, and anxiety (table 3 ). These variables did not explain the improvement in knowledge after reading the guidebook. It seems that it is difficult to predict which patients benefit from the guidebook, and for this reason the guidebook should be distributed to all patients affected by the disease.

Problem solving strategies such as information seeking have been shown to contribute to possible adjustment, and better functional status $^{1314}$ in chronic diseases. On this basis, it might be expected that the improvement in knowledge would reduce the load on other coping mechanisms. However, we could not detect any changes in psychological parameters in this study, nor did the coping profile of the patients affect knowledge after reading the guidebook. It is our opinion that the clear improvement in knowledge is sufficient proof that comprehensive guidebooks are of value for patients with chronic diseases such as SLE.

This study was supported by the Sigrid Juselius Foundation, the Gyllenberg Foundation, and the Arthritis Foundation in Finland. Yriö $T$ Konttinen is a senior investigator of the Academy of Finland. The voluntary participation of the officials and patients of the Finnish Lupus Society is gratefully acknowledged.

1 Schur P H Clinical features of SLE. In: Kelley W N, Harris E D, Ruddy S, Sledge C B, eds. Textbook of rheumatology. E D, Ruddy S, Sledge C B, eds. Textbook of rhen

2 Darby P L, Schmidt P J. Psychiatric consultations in rheu matology: a review of 100 cases. Can $\mathcal{F}$ Psychiatry 1988; 33 $290-3$.

3 Fowles D C. The future arousal model: implications of Gray's two factors theory for heart rate, electrodermal activity and psychopathy. Psychophysiology 1980; 17: 87-104.

4 Pennebaker J W, Susman J R. Disclosure of traumas and psychosomatic processes. Soc Sci Med 1988; 3: 327-32.

5 Helve T. Lupus erythematosus disseminatus. Prevalence in Finland, immunologic monitoring and prognosis [thesis] Helsinki: University of Helsinki, 1984.

6 Tan E M, Cohen A S, Fries J F, Masi A T. The revised criteria for the classification of systemic lupus erythematosus. for the classification of system
Arthritis Rheum 1982; 25: 1271-7.

7 Sandelin S. Self and education. Commentationes Scientiarum Socialium, No. 16. Helsinki: Societas Scientiarum Fennica 1981

8 Anderson K O, Breadley L A, Young L D, McDaniel L K, Wise C M. Rheumatoid arthritis: review of psychological factors related to etiology, effects and treatment. Psycho Bull 1985; 98: 358-87.

9 Baum J. A review of the psychological aspects of rheumatic diseases. Semin Arthritis Rheum 1982; 11: 352-61.

10 Afifi A A, Azen S P. Factor analysis. In: Statistical analysis. A computer oriented approach. 2 nd ed. New York: Academic Press, 1979: 324-41.

11 Afifi A A, Azen S P. One-way analysis of variance. In: Statistical analysis. A computer oriented approach. 2 nd ed. New tical analysis. A computer oriented approc

12 Afifi A A, Azen S P. Stepwise regression. In: Statistical analysis. A computer oriented approach. 2nd ed. New York: analysis. A computer oriented appro

13 Felton B J, Revenson T L. Coping with chronic disease: a study of illness controllability and influence of coping strategies on psychological adjustment. $\mathcal{F}$ Consult Clin Psychol 1984; 52: 343-53

14 Parker J, McRae C, Smarr K, Beck N, Frank R, Anderson S, Waller S. Coping strategies in rheumatoid arthritis. f Rheumatol 1988; 15: 1376-83. 